\title{
Teaching optics with the centennial universal lantern
}

\section{João Carvalhal, Marisa Monteiro, Manuel Bastos Marques}

M. João Carvalhal, Marisa Monteiro, Manuel B. Bastos Marques, "Teaching optics with the centennial universal lantern," Proc. SPIE 9289, 12th Education and Training in Optics and Photonics Conference, 92891I (17 July 2014); doi: $10.1117 / 12.2070785$

SPIE Event: 12th Education and Training in Optics and Photonics Conference, 2013, Porto, Portugal 


\title{
Teaching Optics with the centennial universal lantern
}

\author{
M. João Carvalhal ${ }^{\mathrm{a}}$, Marisa Monteiro ${ }^{\mathrm{a}}$, Manuel B. Marques**b \\ ${ }^{a}$ Museu de Ciência da Universidade do Porto, Reitoria da Universidade, Pr. Gomes Teixeira 4099- \\ 002 Porto; Portugal; bFaculdade de Ciências da Universidade do Porto - DFA and INESC Porto, \\ Rua do Campo Alegre 687, 4169-007 Porto, Portugal
}

\begin{abstract}
A projection apparatus was bought in 1909 by the Physics Cabinet of the Polytechnic Academy (predecessor to the University of Porto's Faculty of Science) in order to present various physics experiments, mostly in the realm of Optics, to a large student audience. A stout and impressive mahogany and brass piece, with a voltaic arc lighting system, it was manufactured by the firm E. Leybold's Nachfölger, based in Chemnitz (Germany), already with a worldwide reputation as a supplier of teaching instruments and equipment to superior schools and universities. It was sold along with an extensive set of accessories, allowing for demonstrations in geometrical optics, spectrum analysis, interferometry, diffraction, polarization and double refraction. Two extra attachments, one for projecting microscopic objects, and the other for the projection of gypsum preparations in polarized light, added to the versatility of this lantern, appropriately dubbed of universal use. Both apparatus and accessories are presently to be found in the collection of the Museum of Science of our University. On studying them, we have come to the conclusion that many classical experiments in Optics may be displayed, without great effort and in an attractive manner. The adaptation to present day usage takes no more than the replacement of the lantern's voltaic arc by a suitable and safer light source. It so happens that a hundred-year old projection apparatus, fitted with a set of purposely designed add-ons, becomes so effective as its modern counterparts.
\end{abstract}

Keywords: Museum, Teaching Optics, Projection

\section{INTRODUCTION}

The magic lantern, whose origin is unclear (Christiaan Huyghens is credited with having built the first magic lantern around 1660) was an important piece of apparatus in the showmen's gear by the end of the eighteenth century. With low intensity lighting sources, the images projected were dim, which, to a certain point, explains why these shows were called "phantasmagoria".

The emergence of brighter sources during the nineteenth century, such as limelight, the voltaic arc and later, the incandescent filament lamp, enabled the use of the magic lantern in large theatre rooms, for educational purposes. The Royal Institution and the Royal Polytechnic Institution of London resorted to them for their science lectures. Trade catalogues of scientific instrument makers routinely show a few models, soon referred to as projection apparatus or optical lanterns, specifically dedicated to teaching. They associate the projection of glass slides, many of them with mechanic motion, to the ability of performing experiments of Physical and Geometrical Optics; some models comprise a microscope, thereby replacing the solar microscope that had been used since the eighteenth century ${ }^{2}$.

By 1890 , projection apparatus were already being adopted systematically as teaching aids in the natural sciences and medicine courses. Dedicated at first to slide projection, they came to be sold with a wide array of accessories for various purposes. Real-time experiments in Physics, Chemistry and Biology can thus be projected before large audiences, where quantitative analysis also becomes possible through the observation of transparent scale instruments, such as thermometers or galvanometers ${ }^{3}$.

\section{HISTORY}

In late 1909, the Physics Cabinet of the Polytechnic Academy of Porto - predecessor to the Faculty of Science of the University of Porto - bought from the German company E. Leybold's Nachfölger, based in Köln, the so-called universal projection apparatus, with an extensive set of accessories. It was the first purchase from this company, and the choice for

\footnotetext{
* mbmarque@ @fc.up.pt; phone +351 220402301; fax +351 220402437
} 
this particular projector was made over the various projection apparatus supplied by its most direct rival Max Kohl (Chemnitz, Germany), from whom the Cabinet had been ordering scientific instruments since 1903.

We believe that this choice may have followed a visit of a Senior Lecturer at the Physics Cabinet, Professor Francisco de Paula de Azeredo, to Lisbon's Polytechnic School (the ancestor of the Faculty of Science of the University of Lisbon). It is likely that he saw the Leybold's universal projection apparatus bought in 1907 by this School.

It is a very versatile instrument, easy to operate. Besides its normal projection function, it can be used in the demonstration of a variety of Physics experiments, by fitting a number of accessories to the projector's main body, rapidly and with precision, thereby allowing for presentations in front of large audiences.

This apparatus was probably intended to be used with experiments of Physical Optics: the accessories also bought at the time are associated with the observation of phenomena of interference, diffraction, double refraction and polarization of light. However, experiments related to spectrum analysis, and the projection of microscopic preparations, photographs on glass and transparent instruments, either vertically or horizontally oriented, are also possible.

The projection apparatus was then placed in the main lecture room of the Physics Cabinet, on an adjustable height stand also supplied by Leybold (fig.1). It seems to have been used for decades: photographs taken during the 1930's and 1940's let us see it in this room, always at the same place.

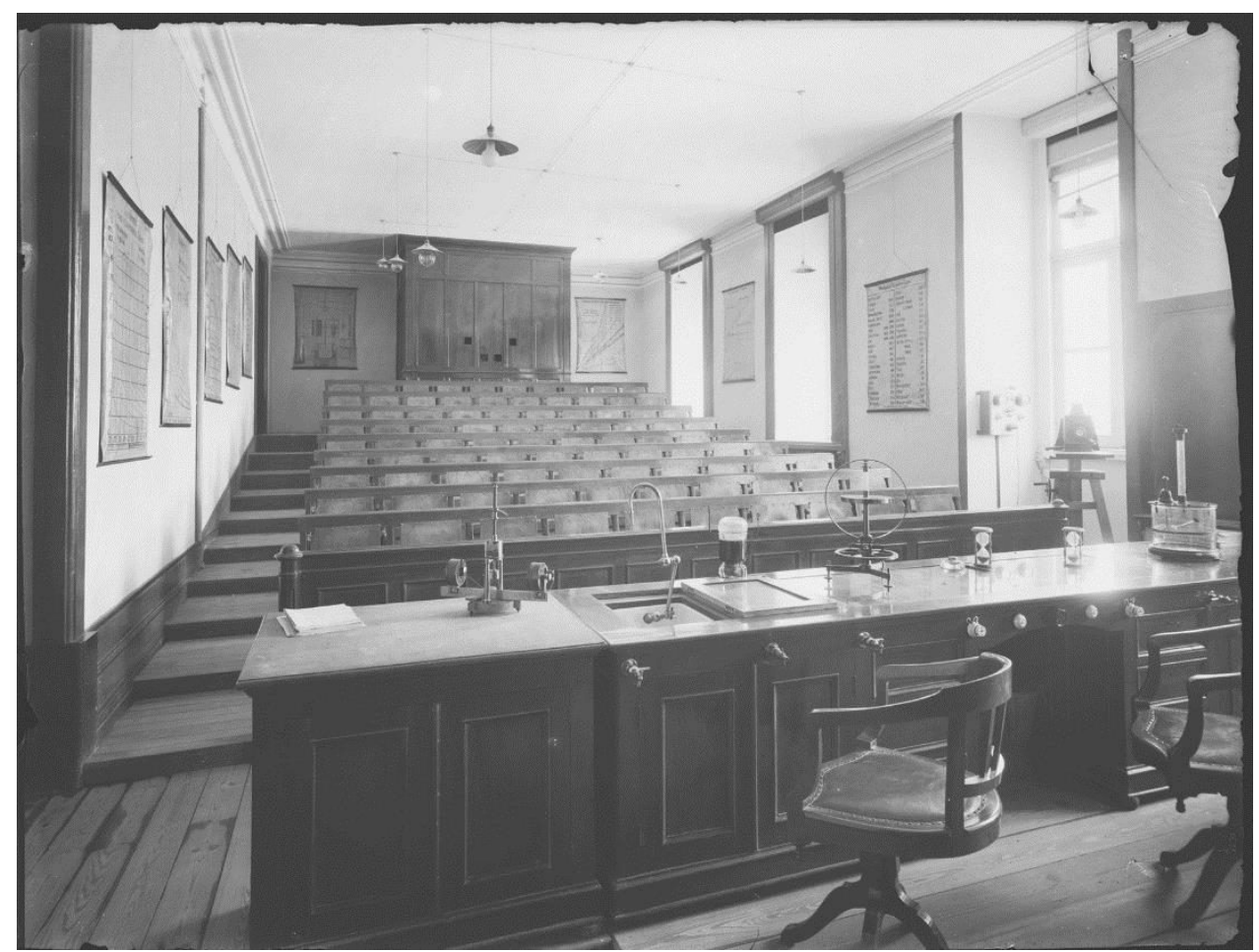

Figure 1. The large Physics theatre room, Faculty of Science, photo by Domingos Alvão, Porto, circa 1925 [courtesy of Centro Português de Fotografia]. The projection apparatus is on the right, by the foremost window.

We have reasons to believe that the projector itself was not manufactured by E. Leybold's Nachfölger. Zoller ${ }^{4}$, on comparing the somewhat small number of workers at the Leybold's factory with the huge number of items listed in their trade catalogues, states that until World War II, this company may have resorted extensively to other scientific instrument makers, so that a significant part of their sales were actually retail sales.

It so happens that this projector is similar, in every way except for the source of light, to the one that had been advertised by the London-based firm Newton \& Co. ${ }^{5}$ since 1894. In fact, a patent with $\mathrm{n}^{\circ} 17059^{6}$ (fig.2a), regarding a Science Lantern, was applied for in 1893 by Herbert Charles Newton (1859-?), son of Frederick Newton (1824-1909), then owner of Newton \& Co. (H. C. himself would be running the company by $1897^{7,8}$ ). The features described in the patent match those that can be found in this projector: the two lenses that make up the condenser fit in separate frames, the outer one turning on 
horizontal hinges; a rod to be fitted to this outer frame, with a rack-work on which the objective moves; and the use of a total reflection prism that can be used also as an erecting prism. Already in 1894 a commercial ad of a new patent "Demonstrator's Lantern", is published in the Optical Magic Lantern Journal, claiming to be "the most simple and efficient Single Lantern yet constructed for general scientific work". A similar ad can be found in manuals for lantern operators (fig.2b).

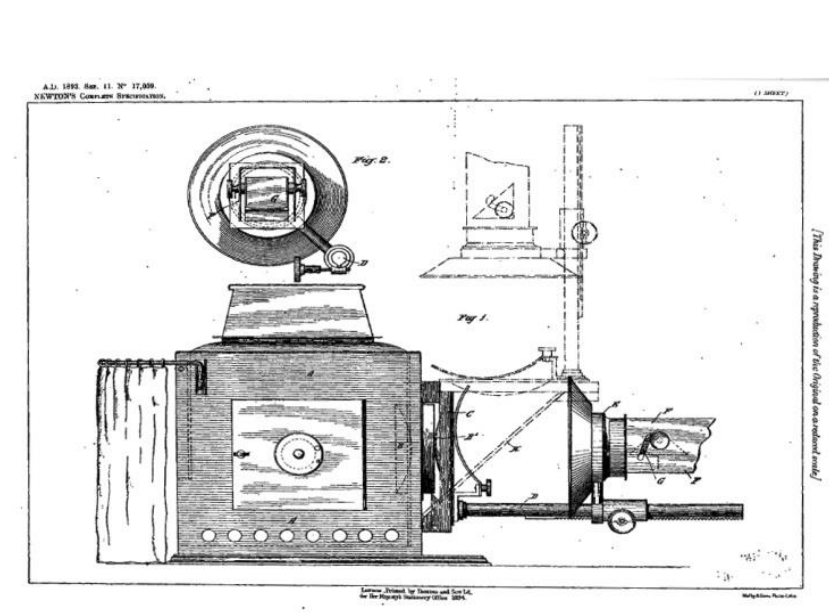

(a)

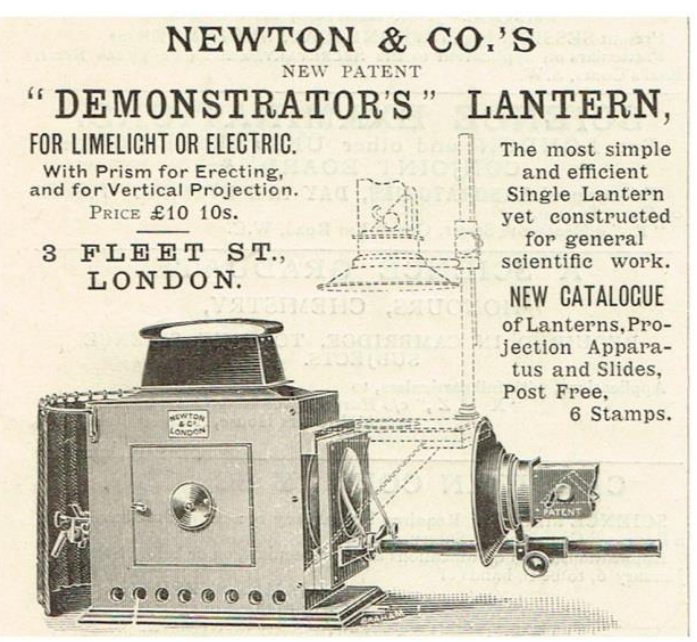

(b)

Figure 2. (a) Drawing contained in the Patent $n^{\circ} 17059$, applied for in $1893^{6}$. (b) Advertisement by Newton \& Co., $1895^{9}$. The radiant perceived is limelight, also object of a patent applied for in 1894 by H. C. Newton (Patent $\left.n^{\circ} 12572\right)^{10}$.

A few other findings contribute to this assertion: the printing stamps of some of the accessories shown in pages 109 and 113 of the "Catalogue of Physical Apparatus, constructed by E. Leybold's Nachfölger"11, are perfect matches of those employed in contemporary Optics textbooks, the only difference being the absence of Newton \& Co.'s signature in the first $^{3,9}$. On the other hand, it should be noted that, in the same catalogue, a few items are clearly referred to as Leybold's own inventions. That is the case of item number 2187, the universal arc lamp for automatic and hand feed; of the stand with catalogue entry number 2582, and of "Leybold's Glass Vessels for projection and other experiments".

It is therefore possible that only the authorship of the accessories designed to perform the diverse experiments of Physical Optics can be attributed to Leybold, as such accessories were nowhere to be found in the trade catalogues, manuals and textbooks consulted: the same experiments were performed with the aid of different setups, or attachments, as shown, for instance, in the contemporary Max Kohl's catalogue12, and in both books Lewis Wright (1838-1905) wrote on the subject $^{3,13}$ (Evidence was found that Wright actually maintained collaboration with Newton \& Co., while his son, Russell Stuart Wright (1876-1961), was a business associate of Newton \& Co. between 1915 and $1920^{14}$ ).

\section{THE UNIVERSAL PROJECTION APPARATUS}

The universal projection apparatus is aesthetically a very handsome object, a stout polished mahogany body with some varnished brass elements (fig.3). The attachments are also fine objects, made partially or completely in varnished brass, which can be fastened to the projector with ease and accuracy.

The projector's body is internally lined with a black metal casing, built slightly away from the outer wooden casing, in order to keep it cool through air. This way, it will not get overheated or burnt, offering no danger to the lanternist. Acces s to the lantern's interior is provided by two side doors, with blue glass circular windows, for observation of the radiant, or source of light (particularly in the case of limelight). Brass discs cover the circular openings during operation, while muscovite discs fill in the corresponding openings in the metal casing. The lantern is open at the rear side, to allow in the source of light, which used to be screened by a black velvet curtain. The space inside is adequate for the use of either limelight or of a voltaic arc.

Holes drilled at the base of the side walls and a metallic chimney at the top ensure cooling by air circulation, allowing the projector to work for hours at a time. The flat heated top is convenient for keeping fluids and objects warm, while projection and experimental work takes place ${ }^{3}$. 

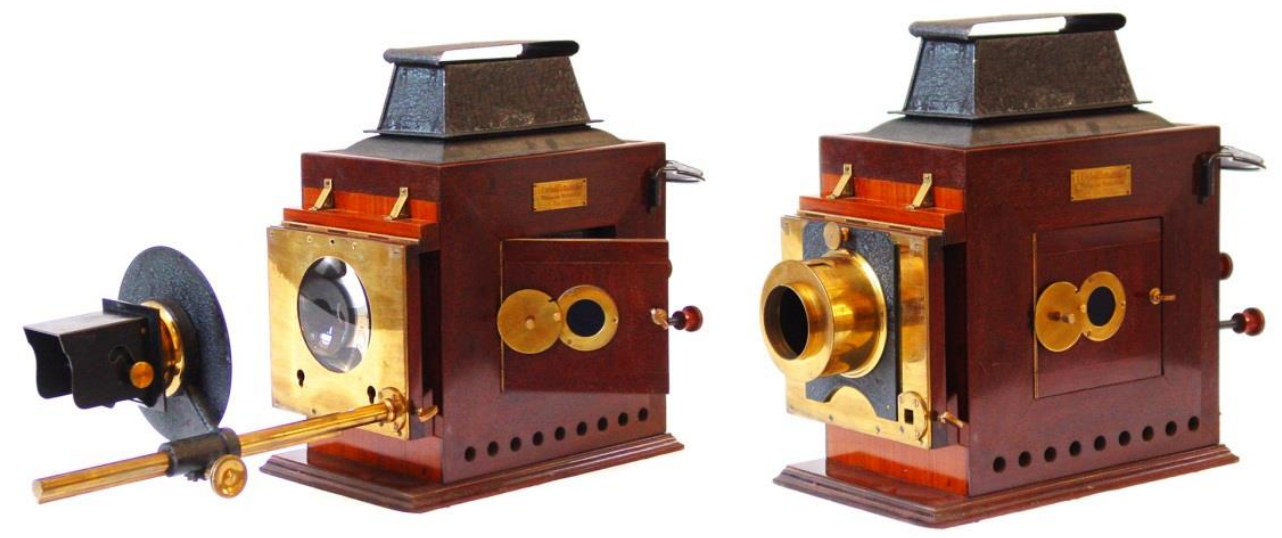

Figure 3. The projection apparatus.

The condenser consists of two plano-convex lenses with the convex sides turned inwards; their diameter is $110 \mathrm{~mm}$, which enabled the projection of all glass transparencies ordinarily obtainable at the time $(8,5 \times 8,5 \mathrm{~cm} \mathrm{or} 8,5 \times 10 \mathrm{~cm})$. The distance they are kept apart is such that the condenser can be considered achromatic for all practical purposes (only the boundary of the circular illuminated area is coloured). This type of condenser was the most commonly found in fine quality lanterns in those days ${ }^{3}$.

One of the lenses is mounted on a brass garniture, at the front wall of the projector; the other one fits a wooden frame, bound with brass, hinged to the upper part of the front so as to be turned upwards. In this way, the frame - and the condenser's second lens - can be placed horizontally, by sliding in, between guiding folds, a metallic plate or mirror, tilted at $45^{\circ}$. Projection of experiments performed horizontally becomes possible when adopting such configuration (fig.4a), provided that a partially or completely transparent instrument is used, for instance, for the observation of magnetic field lines (fig.4b), of chemical reactions, etc. The addition of the total reflection prism, as coupled to the objective, enables the projection on to a screen in front of the lantern.

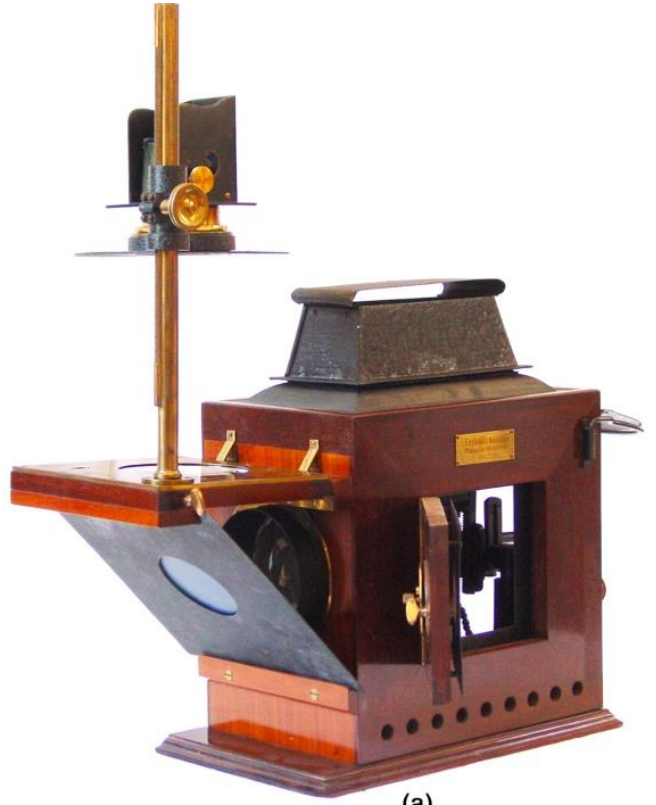

(a)

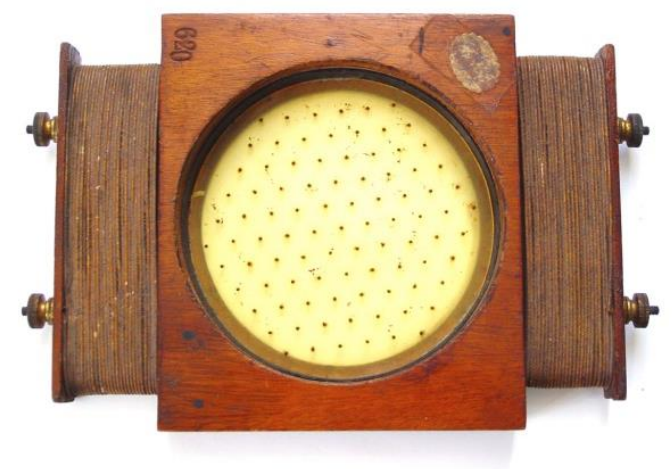

(b)

Figure 4. (a) The projection apparatus prepared for experiments performed horizontally. (b) Ewing's apparatus, where tiny magnetic needles (now missing) on an array of pins materialize magnetic field lines.

With this configuration, it is also possible, with the help of a stylus, to make drawings, write formulae or short texts, on small smoked glass plates, laid on the condenser's second lens. Information that would otherwise be written on a 
blackboard can thus be presented to an audience, in the same lighting conditions as usually required by projections. The lantern then rises to the standard of the overhead projector that became so popular in the last decades of the twentieth century and has now fallen into disuse by the introduction of datashow multimedia projectors.

With the frame and second lens turned down (fig.5a), it is possible to project ahead transparent on-going experiments and devices placed in the slide holder and held in position by the springs - such as chemical reactions, precipitations and crystallizations, and the decomposition of water through electrolysis, all of them performed in prismatic troughs - or adequately positioned between the condenser and the objective. In this configuration, the total reflection prism is also employed, this time for obtaining erect images on the screen. The Physics Cabinet kept a few instruments to be used with the projection apparatus in any of these configurations (figures $5 \mathrm{~b}$ and $5 \mathrm{c}$ ). It is also to this movable flap that most of the accessories for the Physical Optics experiments are attached.

The objective consists of an achromatic lens of $50 \mathrm{~mm}$ diameter and $200 \mathrm{~mm}$ focal length, inserted in a metallic diaphragm of $180 \mathrm{~mm}$ diameter. The focusing system is easy and effective: the objective-diaphragm assembly is moved back and forth, by means of a rack and pinion, along a rod fitted to the movable frame (fig.5a).

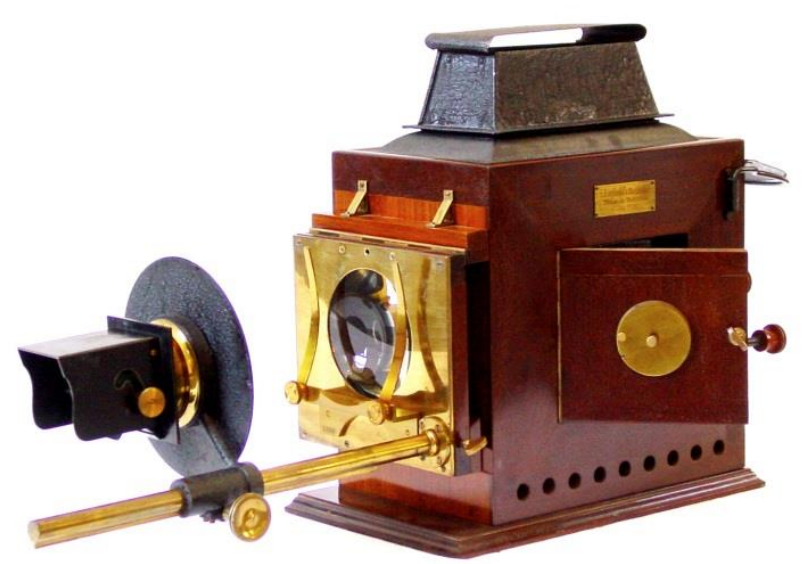

(a)

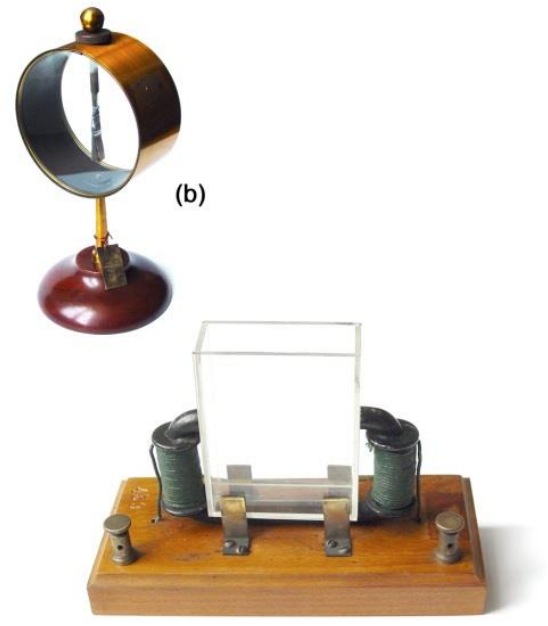

(c)

Figure 5. (a) The projection apparatus prepared for experiments performed vertically. (b) Beetz' leaf electroscope. (c) Töpler's apparatus, for materializing magnetic field lines through iron filings suspended in liquid paraffin.

A voltaic arc is the adopted source of light (fig.6a). Leybold's catalogue shows photometric relationships between different sources and a four-wick paraffin lamp, taken as unity, only to conclude that electric arc light offers, by far, the best performance. But considerable light intensity is not the only requirement for a projection apparatus; for projecting the Physical Optics experiments and microscopic objects, a point source is the ideal source of light, and the voltaic arc was, at the time, the source of light that best met this condition.

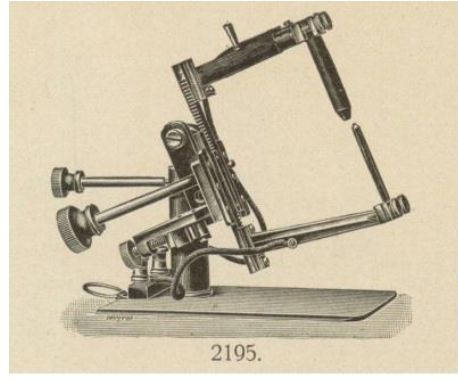

(a)

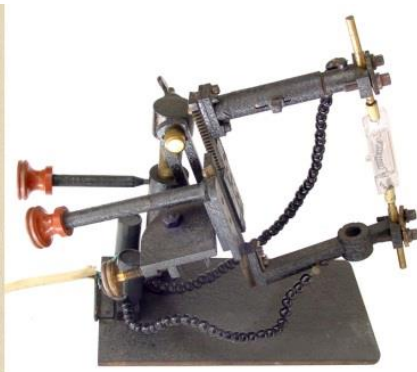

(b)

Figure 6. (a) The voltaic arc lamp, as in the maker's catalogue ${ }^{15}$. (b) The same system, equipped with a tungsten-halogen lamp. 
A hand feed electric arc lamp was bought for this lantern in 1909, whose regulating mechanism is considerably simple: a combination of three screws allows the movement of the carbons toward each other, as well as the arc to be displaced vertically and from side to side; the catalogue itself gives some assistance on how to operate these screws suitably (fig.7), to have the light source adequately centred. The voltaic arc lamp also has the advantage of being able to work with the carbons either upright or tilted.

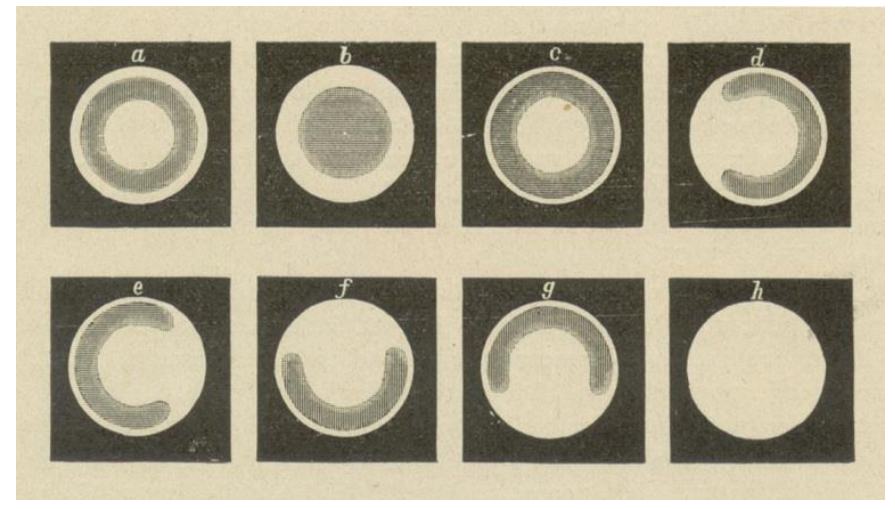

Figure 7. Different positions of the light source as shown in the maker's catalogue ${ }^{15}$ : in "a" and "b", it is too near the condenser, and in "c", it is too far from it; in " $\mathrm{d}$ " and " $\mathrm{e}$ ", the light source is respectively displaced to the right or to the left; in "f" and "g", it is too low and too high, respectively; " $h$ " turns out to be the optimum position, with the circle on screen equally illuminated. These directions are quite important when it comes to slide projection.

In connecting to a supply lead, an additional resistance was needed, as the building's supply voltage, then $110 \mathrm{~V}$, had to be lowered down to $40 \mathrm{~V}$, the voltage required by the voltaic arc. For that purpose, a set of additional resistances was also ordered from Leybold, mounted on a marble slab switch board, equipped with a switch, lead fuses and wall plug. It also included an adjustable resistance, with ammeter and voltmeter, to control the output current. The switchboard was lost; only the ammeter and voltmeter remain and have been identified.

\section{EXPERIMENTS IN PHYSICAL OPTICS}

These experiments seem to be the main utility of this equipment. A wide range of accessories allows us to perform a variety of experiences: interference, diffraction, polarization and double refraction of light. The elements required for each experiment are rigidly mounted on attachments which are fastened, by means of a simple arrangement avoiding screws, to the frame that holds the condenser's outer lens, thereby ensuring the correct alignment of all parts.

\subsection{Interference}

Amplitude-splitting interferometer - this experiment, which is carried out with difficulty when mirror and slit are separate, is performed with the greatest ease by means of this attachment, Fresnel's mirror (fig.8), where these elements are brought together in the same stand in front of the objective. The outcome of the experiment depends only on the operator's ability to achieve the adequate slit aperture, angle by which the second mirror is revolved, and position of the lamp. When a piece of red glass is placed in front of the mirror, the wavelength of the radiation thus obtained can be determined with reasonable accuracy.

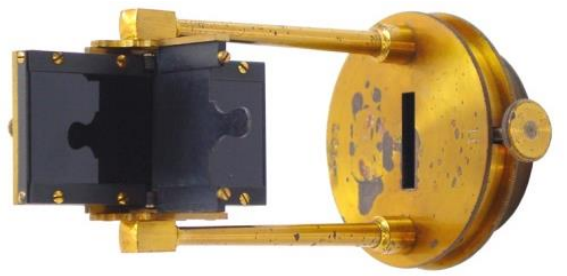

Figure 8. Attachment known as Fresnel's mirror: it combines a slit whose width is adjustable by a screw, a rigid stand for a pair of mirrors, and a sliding screen in the middle. A smaller screw on the back of the second mirror controls the angle between the two mirrors. 
Newton's rings - they can be observed, either in transmission (fig.9a) or in reflection; a proposed experiment consists of limiting the observation of those rings to the central area, with a rectangular slit, and analyse their spectrum through an Amici prism (fig.9b) or a diffraction grating.

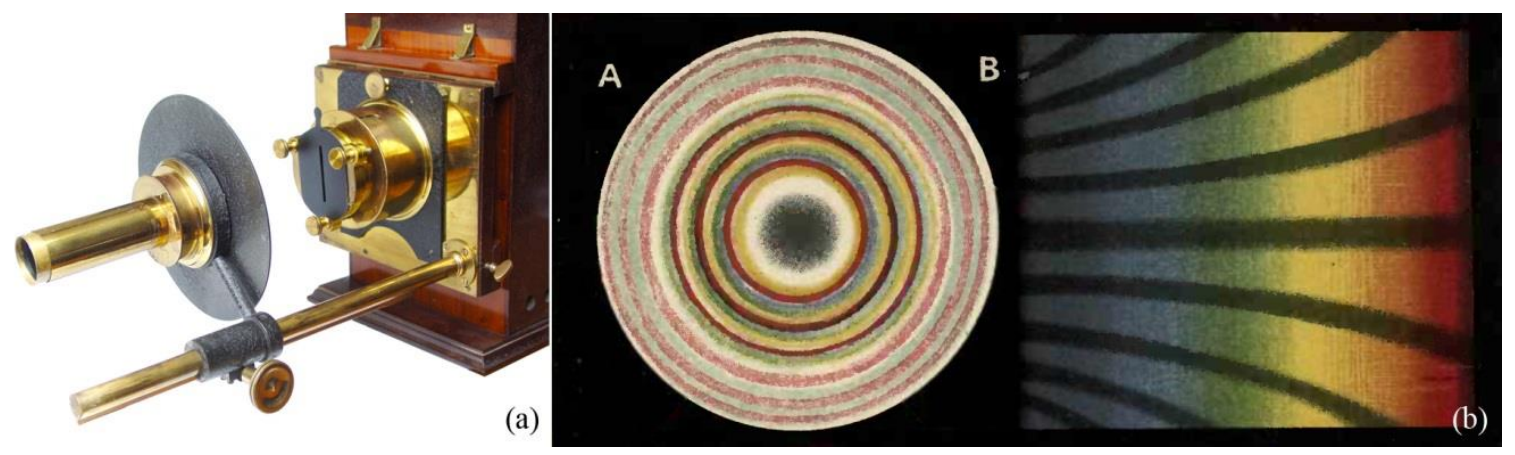

Figure 9. (a) Attachment for the projection of Newton's rings, with slit and Amici prism. (b) The spectra of Newton's rings, as obtained with the Amici prism (from Lewis Wright's "Light: a course of Experimental Optics", 2nd ed., 1892, plate $3{ }^{13}$ ).

\subsection{Diffraction}

The observation of diffraction patterns can be attained through an attachment with a slit whose aperture is adjustable by a micrometre-screw (fig.10). Once again, a quantitative analysis is possible by resorting to coloured glass to restrain the width of the band under analysis: the radiation wavelength can be computed out of the width of the slit and distance between two consecutive coloured bands. A set of diffraction gratings with different constants (fig.11) further extends the possibilities of this equipment, as far as the demonstration of diffraction phenomena is concerned.

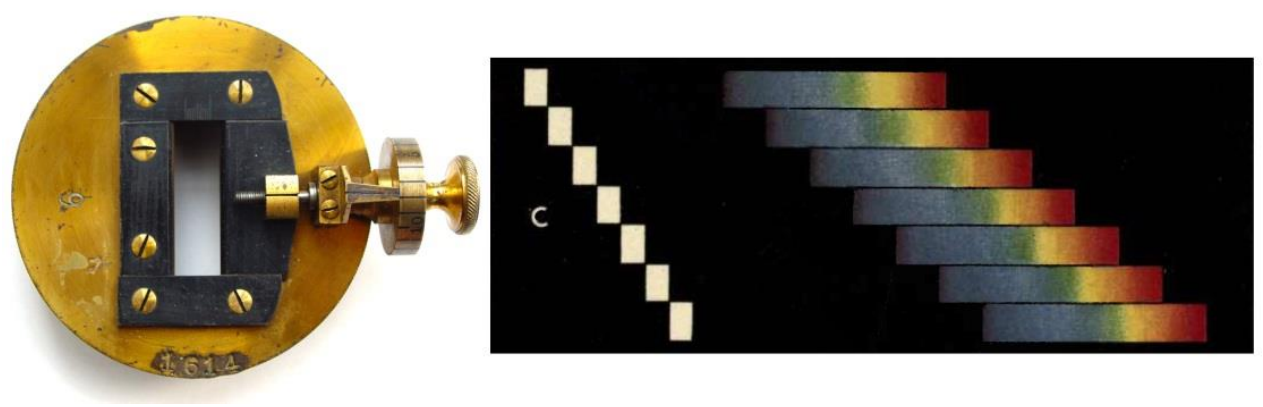

Figure 10. Attachment for experiments on diffraction, with adjustable-width screw, and corresponding spectrum analysis (from Lewis Wright's "Light: a course of Experimental Optics", 2nd ed., 1892, plate $2^{13}$ ).

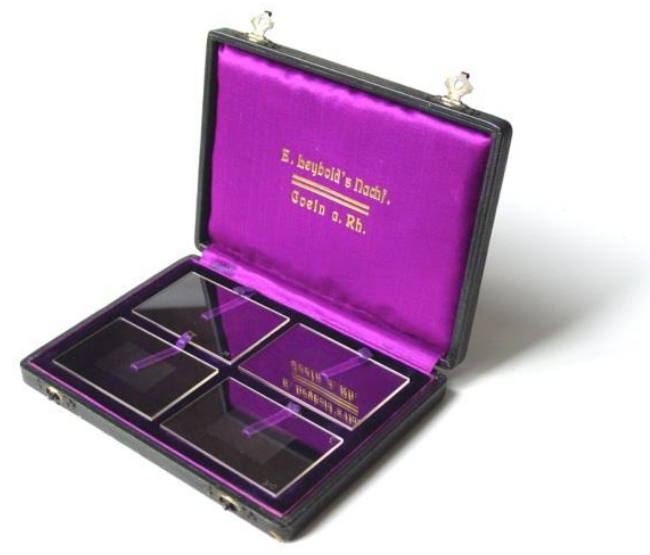

Figure 11. Diffraction gratings with different constants in case. 


\subsection{Polarization and birefringence}

The experimental demonstration of the polarization of light is made possible with the choice of a few attachments (figures $12 \mathrm{a}, 12 \mathrm{~b}$ and 12c). Different elements exchanging positions show that polarization can be obtained through either absorption, reflection or birefringence. Their association and/or replacement is prompt and accurate. The same elements, when combined with a Laurent's quartz plate or left and right handed quartz plates, clarify how a saccharimeter works.
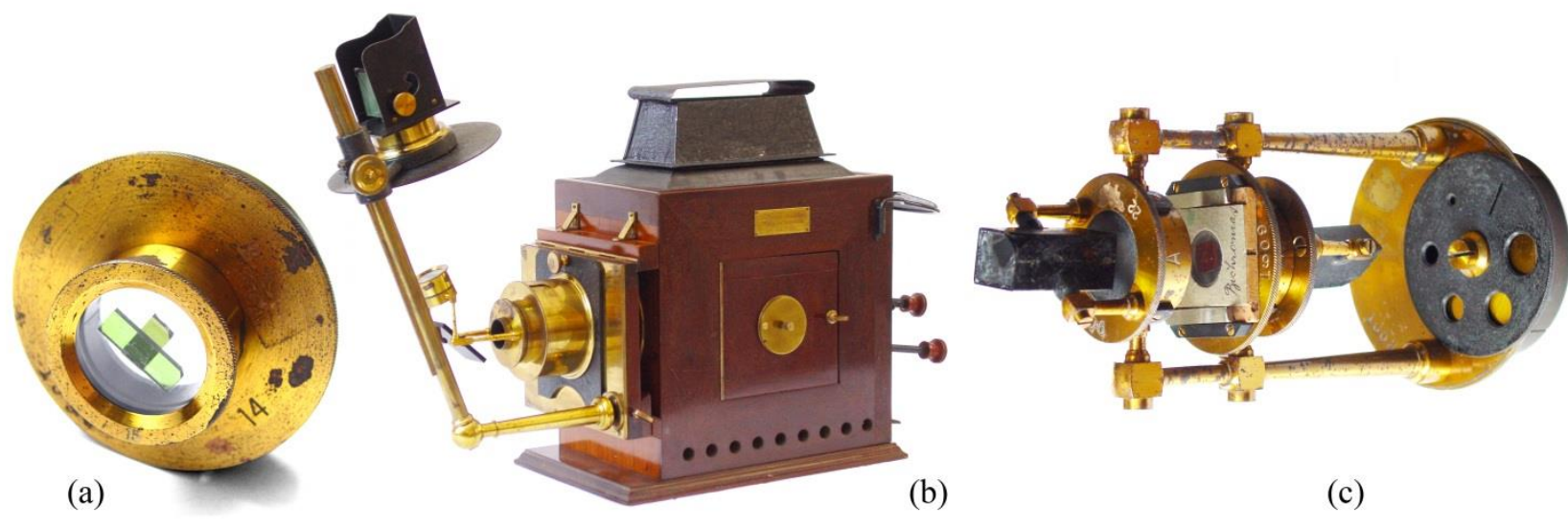

(b)

(c)

Figure 12. (a) Attachment for projection of transmitted light through two tourmaline crystals whose optical axes can be rotated. (b) Setup for experiments on polarization, the polarizing angle $\left(56^{\circ}\right)$ being guaranteed by an auxiliary rigid arm, and the mirror (a piece of black glass) being mounted on the attachment so as to act either as the polarizer - as in this example or as the analyser; (c) Attachment with two fitting rings for the polarizer and the analyser. These can be tourmaline and calcite crystals, or nicols. Mica, gypsum and aragonite plates, etc., can also be interposed between the polarizer and the analyser.

A polariscope ordinarily dubbed as "elbow polariscope", because of its shape, adds to the understanding of polarized light, having a glass pack as the polarizer and a nicol as the analyser (fig.13). This attachment is fastened to the projector and enables the projection of images engraved in gypsum (selenite) which are, basically, preparations of gypsum with unequal thickness. On turning the nicol, the colours pass over to their complementary (fig.14).

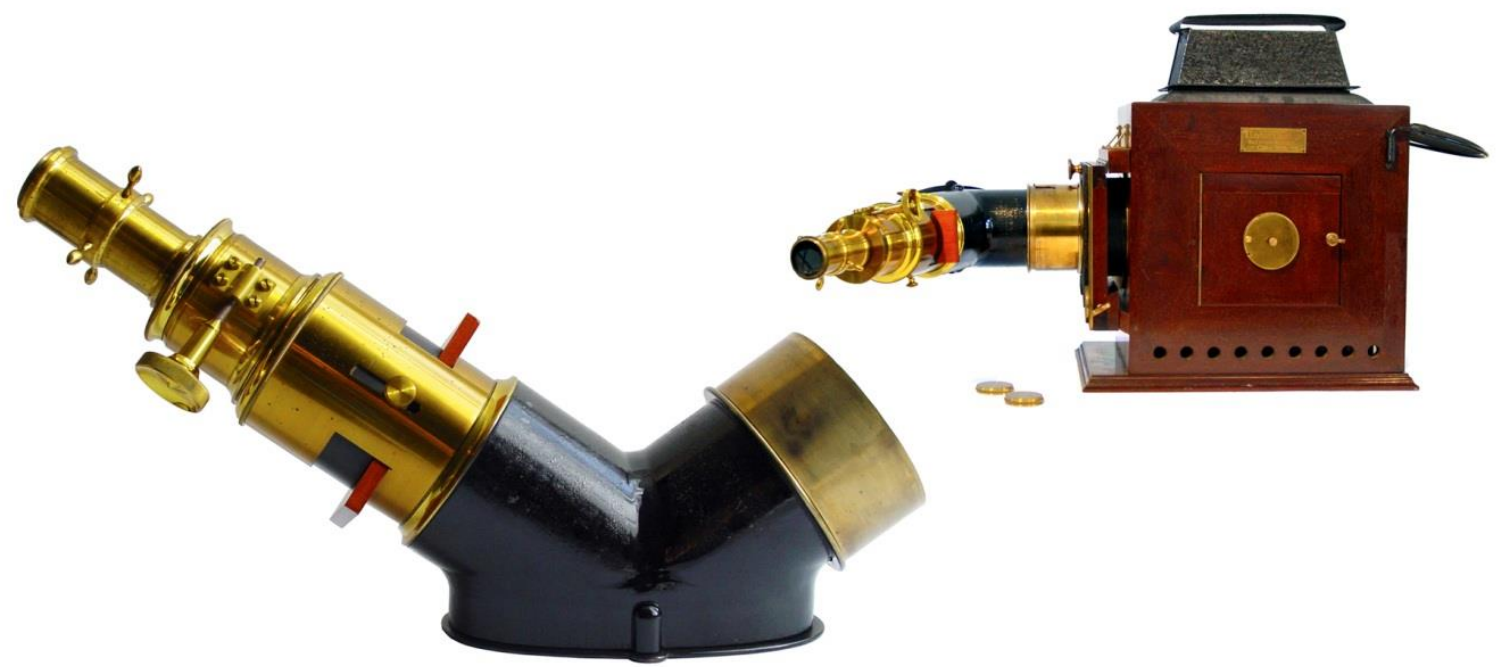

Figure 13. Elbow polariscope attachment and fitting procedure. 

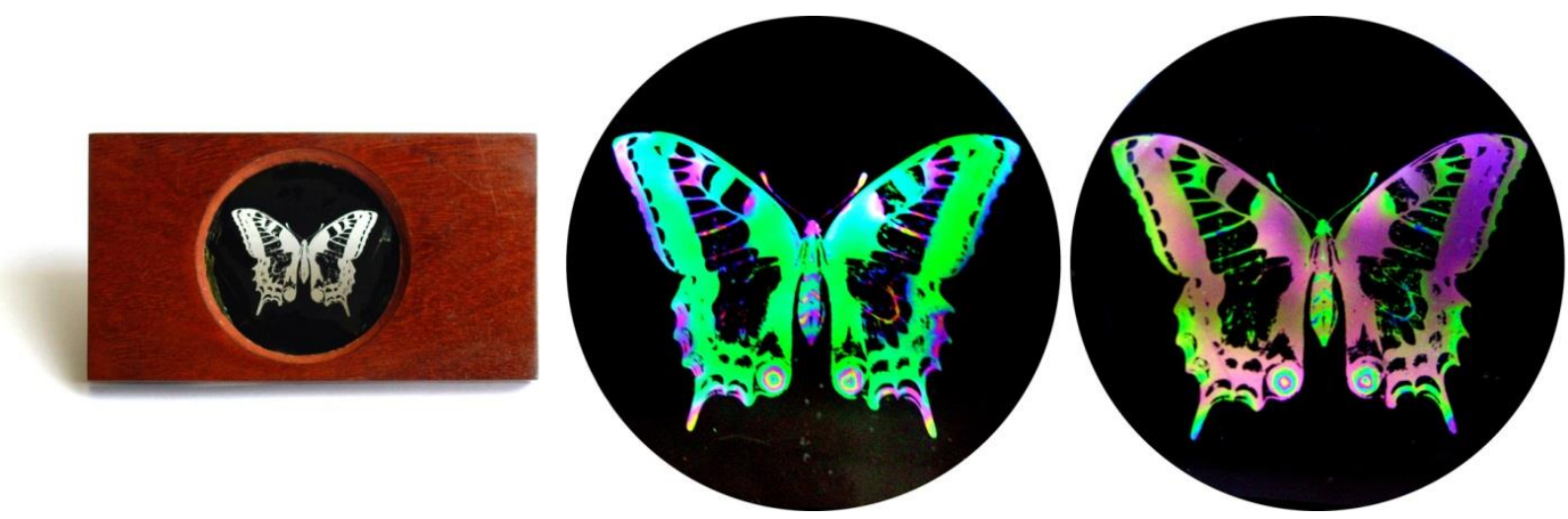

Figure 14. Gypsum preparation for projection in polarized light. Complementary colours as shown by the $90^{\circ}$ rotation of the nicol.

\subsection{Projection of microscopic preparations}

There is still an accessory for the projection of microscopic projections, to be attached to the projector right in front of the condenser (fig.15a). It is designed as a composed optical microscope: a triple-lens assembly places the focus in coincidence with the preparation, and a revolving nosepiece bears three objectives with different magnifications. As the preparations may be damaged by the excessive heat radiating from the voltaic arc, a cylindrical trough filled with distilled water or an alum solution is inserted between the condenser and the microscope, acting as an infrared absorption medium (fig.15b).

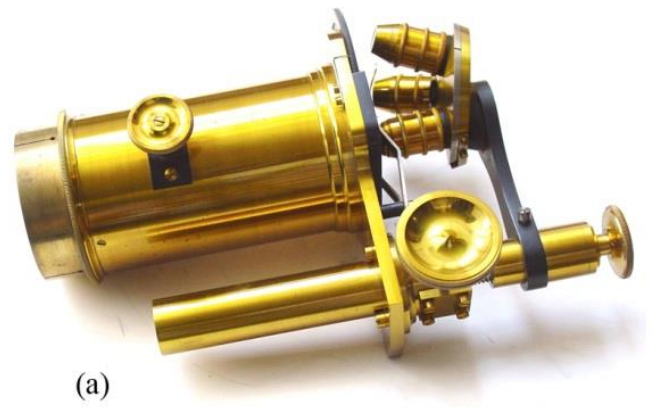

(b)

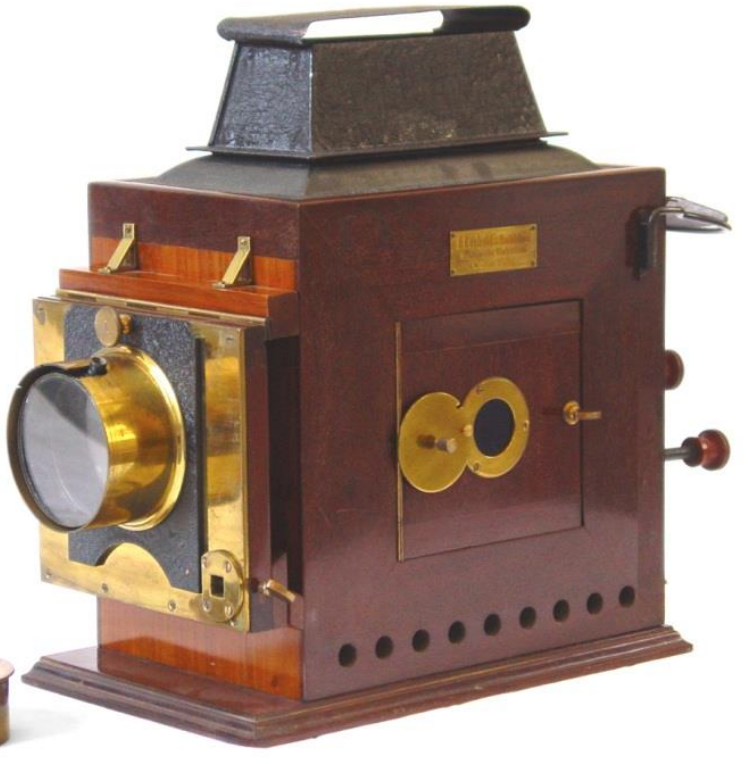

Figure 15. (a) Attachment for projecting microscopic objects. (b) Fitting of the heat absorption trough.

\subsection{Experiments in Geometrical Optics}

Using the lantern as a lighting source, it is possible to set up experiments to demonstrate the principles of Geometrical Optics. Driving the voltaic arc lamp farther from or closer to the condenser, a parallel, convergent or divergent beam is obtained. Accessories such as Tyndall optical apparatus (fig.16), which E. Leybold's Nachfölger also supplied, then allow for the demonstration of Snell's laws of refraction and reflection, as well as of total reflection. 


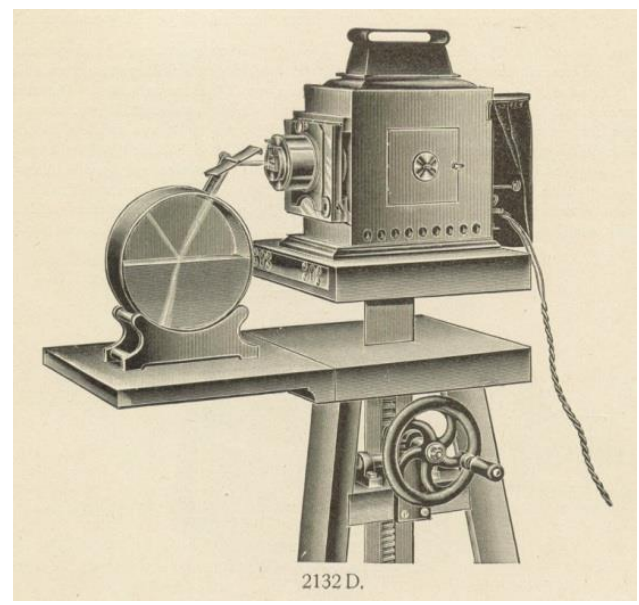

F Figure 16. (a) Arrangement of lantern and Tyndall apparatus on stand, to show reflection and refraction ${ }^{15}$.

The Physics Cabinet did not buy any accessories for this purpose in 1909, which only confirms our conjecture that the projection apparatus was meant for performing mainly demonstrations in Physical Optics. An attachment with arrow for experiments in Geometrical Optics would be bought, however, later in 1912, proving that there may have been some intention of further exploring the utility of this projector.

\section{CONCLUSION}

A hundred years later, this projection apparatus is still surprisingly effective and still functional: its operation depends only on the replacement of the primitive light source by a projection lamp which is appropriate for the experiments on Physical Optics, an approximate point source.

It is possible that an attempt of re-using it has been made in the Physics Laboratory of the Faculty of Science: in last century's fifties or sixties, the radiant was modified (probably at the same time the lead supply voltage was altered from 110 to $220 \mathrm{~V}$ ); the voltaic arc's electrodes have been replaced by two brass rods, to hold a tungsten-halogen projection lamp, a PHILIPS 6366R, $800 \mathrm{~W}$ (fig.6b). However, up to this moment, no record has been found of this upgrade, nor any memory of its working.

Self-contained and versatile, the significant number of Physics experiments that can be demonstrated through projection would surely make it more appealing and cause a greater impact in the minds of young students than the currently used video-projector and computer-drawn diagrams.

\section{REFERENCES}

[1] Hankins, T. L., "How the Magic Lantern Lost Its Magic", Optics \& Photonics News, January, 34-49 (2003).

[2] Hackmann, W., “Annual Invitation Lecture - Spectacular Science through the Magic Lantern”, Bulletin of the Scientific Instrument Society, No. 116, 30-41 (2013).

[3] Wright, L., [Optical Projection, a treatise on the use of the lantern in exhibition and scientific demonstration], 4th ed., Longmans, Green, and Co., London, New York \& Bombay (1906).

[4] Zoller, P., "Physics Experiments for Everyone: German Makers", Bulletin of the Scientific Instrument Society, No. 102, 21-29 (2009).

[5] Holland, J., "Frederick Newton, Citizen", Bulletin of the Scientific Instrument Society, No. 86, 24-26 (2005).

[6] European Patent Office, Espacenet Patent Search, Patent nº GB189317059, http://worldwide.espacenet.com

[7] Gee, B., "The Newtons of Chancery Lane and Fleet Street Revisited. Part I: A Question of Establishment", Bulletin of the Scientific Instrument Society, No. 35, 3-6 (1992).

[8] Gee, B., "The Newtons of Chancery Lane and Fleet Street Revisited. Part II: The Fleet Street Business and Other Genealogy", Bulletin of the Scientific Instrument Society, No. 36, 12-14 (1993).

[9] Bayley, R. C., [Modern magic Lanterns, A guide to the management of the optical lantern, for the use of entertainers, lecturers, photographers, teachers, and others], L. Upcott Gill, London, 83-99 (1895). 
[10] European Patent Office, Espacenet Patent Search, Patent nº GB189412572, http://worldwide.espacenet.com

[11]E. Leybold's Nachfölger, [Catalogue of Physical Apparatus, constructed by E. Leybold's Nachfölger, Cologne], A. B. C. Code 5th Ed., 93-120 (190- ). This is the English version of the German catalogue prepared by R. Bernoulli, from the distinct Bernoulli family, then the company's resident scientist, which was published in 1904 and is commonly identified as Jubiläums-Katalog.

[12] Max Kohl, [Appareils de Physique], Catalogue n²2, Impr. Hugo Wilisch, Chemnitz (1905).

[13] Wright, L., [Light, a course of experimental optics chiefly with the lantern], 2nd ed., Macmillan and Co., London \& New York, (1892).

[14] Lucerna - The Magic Lantern Web Resource, www.slides.uni-trier.de

[15]E. Leybold's Nachfölger, [Einrichtungen und Apparate für den Physikalischen Unterricht sowie für Übungen im Praktikum nebst Literaturangaben und Gebrauchsanweisungen Von E. Leybold's Nachfolger, Cöln A. Rh.], A. B. C. Code 5th Edition, 302-332 (1904), (Jubiläums-Katalog). 